\title{
Adília e Baudelaire: leituras do fim
}

\section{Celia Pedrosa}

- (BAUDELAIRE, Charles. "O meu coração a nu". Em O meu coração a nu, precedido de Fogachos. Lisboa: Guimarães, 1988.)
Adília Lopes publicou seu primeiro livro de poemas em $1985,{ }^{1}$ pouco mais de cem anos após a publicação das Fleurs du Mal de Baudelaire. Esse dado permite colocá-los juntos em um lugar significativo, o fim de século. E especialmente significativo nesse caso, na medida em que o fin-du-siècle XIX trouxe, e continua trazendo, importante contribuição para a reflexão sobre a literatura - até inclusive esses nossos dias, em que se confundem o final do século XX e o início do XXI e se intensificam os questionamentos sobre a herança moderna, sobre o próprio significado de herança e de modernidade.

Não por acaso, é de um texto baudelairiano que Walter Benjamin vai desentranhar a formulação de sua já célebre tese IX sobre o conceito de história, de modo a inclusive possibilitar uma outra leitura da relação entre fim-de-século e decadentismo, e uma nova reflexão sobre a experiência do tempo, no tempo. Não custa lembrar mais uma vez Baudelaire:

Perdido neste mundo adverso, incomodado pela multitude, pareço-me com um homem desiludido cujo olhar, quando se volta para trás e procura fixar-se nos anos revolutos, não se apercebe de mais do que desilusão e amargura, e que, se olha em frente, não consegue distinguir nada de novo, nem ensinamentos nem dor.

No filósofo, essas palavras vão produzir uma ressonância que, remetendo também à pintura de Paul Klee, mistura arte, religião e política, reinventa o messianismo e não cessa de estimular novas interpretaçōes:

$\mathrm{O}$ anjo da história deve ter esse aspecto. Seu rosto está dirigido para o passado. Onde nós vemos uma cadeia de acontecimentos, ele vê uma catástrofe única, que acumula incansavelmente ruína sobre ruína e as dispersa a nossos pés. Ele gostaria de deter-se para acordar os mortos e juntar os fragmentos. Mas uma tempestade sopra do paraíso e prende-se em suas asas com tanta força que ele não po-

\footnotetext{
${ }^{1}$ Adília publicou desde então dezenove livros de poemas. Os quinze primeiros foram reunidos no volume Obra, de 2000 (Lisboa: Mariposa Azual, 2000). Depois foram editados sucessivamente os outros quatro volumes: A Mulher-a-dias (Lisboa: \&etc., 2002), César a César (Lisboa: \&etc., 2003), Poemas novos (Lisboa: \&etc., 2004) e Le Vitraillla nuit A árvore cortada (Lisboa: \&etc., 2006).
} 
de mais fechá-las. Essa tempestade o impele irresistivelmente para o futuro, ao qual ele vira as costas, enquanto o amontoado de ruínas cresce até o céu. Essa tempestade é o que chamamos progresso.

Catástrofe e tempestade conturbam aí a imagem linear e evolutiva do tempo, representando o movimento que empurra o sujeito moderno - figurado agora como anjo caído e cego - para o desconhecido. De fato, ao compreender sua contemporaneidade através das imagens da ruína, da decadência e do emparedamento, Baudelaire contribui para problematizar a concepção de modernidade como ruptura com o passado, associada a um projeto demiúrgico de colonização do futuro. A partir dessa perspectiva, a arte e a literatura passam a representar um gesto profanatório, e dúplice, portanto, pois que reivindicam a própria consciência da temporalidade enquanto processo de transformação, característica do moderno, para ao mesmo tempo lhe atribuírem um uso outro, invertido mesmo, e por isso irônico, que coloca em crise os valores de iluminação e progressismo.

Aqui cabe uma distinção, importante para a avaliação da descendência baudelairiana, até hoje inclusive, conforme nos mostrará a poesia de Adília Lopes. ${ }^{2}$ Ela diz respeito à recuperação da diferença entre ironia e paródia. Como paródico, vai se definir o discurso propriamente moderno, fundado em uma autoconsciência que reivindica o outro - outro tempo, outro espaço, outra identidade, outra linguagem - para negá-lo e assim poder reafirmar-se. Como irônico, ao contrário, compreende-se o discurso impropriamente moderno - a ironia é sempre marca de uma impropriedade - em que a relação com o outro supõe colocá-lo, mas também colocar-se a si mesmo simultaneamente em jogo, suspendendo identidades, dicotomias, hierarquizações.

Não é por outro motivo que na poesia baudelairiana a ironia está intrinsecamente associada à visão do e no espelho, nela apre-

\footnotetext{
${ }^{2}$ Acredito que a compreensão das relações entre a literatura contemporânea e a literatura moderna, em suas diferentes manifestaçōes, possa ganhar com uma maior atenção à ironia, para além da mera oposição paródia-pastiche, na qual se ignora a duplicidade de valor que aquela mobilizaria. Cf. a esse respeito as considerações de Roland Barthes sobre a novela $S / Z$ de Balzac (BARTHES, R. $S / Z$. Paris, Seuil, 1970: 50-52). Para a ampliação dessa discussão, é interessante, sob outro ângulo o texto de Giorgio Agamben, "Paródia" (AGAMBEN, G. Profanaçôes. Lisboa: Cotovia, 2005: 51-73). Rosa Maria Martelo destaca a importância da ironia na compreensão da poesia de Adília Lopes (MARTELO, R. "Adília Lopes ironista”. Em Scripta - Revista do Programa de Pós-graduação em Letras e do Centro de Estudos Luso-afro-brasileiros da PUC de Minas Gerais, vol. 8, no $15,2^{\circ}$ semestre de 2004).
} 
- (STAROBINSKI, Jean. La mélancolie dans Le miroir. Trois études baudelairiens. Paris: Julliard, 1989.)

(BAudelaire, C. "O meu coração a nu". Op. cit.: 53.)

(JENNY, Laurent. "Fictions du moi et figurations du moi". Em RABATÉ, Dominique (org.). Figures du sujet lyrique. Paris: Presses Unversitaires de France, 1996.)

(BAUDELAIRE, C. "O meu coração a nu". Op. cit.: 25.)

(BAUDELAIRE, C. "O meu coração a nu". Op. cit.: 72 .) sentado, no poema "O Irremediável", como "Farol irônico, infernal,/ Archote aceso a Satanás/ Consolo e glória sem iguais/ A consciência dentro do mal". Pois através dela é mobilizada a desestabilização reflexiva tanto da experiência do real quanto da própria subjetividade, ambas então transformadas em imagens incertas e efêmeras, conforme analisa Jean Starobinski no livro La mélancolie dans le miroir. Trois études baudelairiens

Profanação, ironia, desestabilização - essas são as marcas que vão caracterizar a relação entre o artista e a vida moderna, tal como compreendida pelo poeta. Ele a encena através dos desdobramentos de um eu lírico que já pode se tornar caminhante anônimo, em meio à multidão, porque libertado do peso e do brilho de sua aura, perdida em meio ao trânsito célere dos bulevares. Mas essa nova liberdade é exercitada, ironicamente, claro, num cenário restrito e sombrio, composto, como se viu, de restos alegóricos do passado e imagens presentes de miséria e dor, em que a própria idéia de poesia parece perder todo o sentido. ${ }^{3}$

Desse modo integram-se metonimicamente, desestabilizadas, tanto a imagem moderna de cidade quanto a imagem moderna de história, num movimento duplo, portanto, de descontextualização e recontextualização. Esse movimento remete ao que articula vaporização e centralização, como o próprio Baudelaire o identifica a propósito dos processos de subjetivação em seus textos. Podemos associar a ambos, ainda, aquele processo que Laurent Jenny identifica na enunciação baudelairiana, segundo ele um misto de figuração e ficcionalização, que afirma a subjetividade remetendo-a, no entanto, a um estatuto instável, transubjetivo, e legitimando assim a impropriedade e a proliferação como valores éticos e estéticos.

Lembre-se a esse propósito a associação baudelairiana de arte, amor e religião: "O amor é o gosto da prostituição. Nem existe prazer nobre que não possa reconduzir-se à prostituição. Num espetáculo, num baile, cada um frui todos. O que é a arte? Prostituição". "O ser mais prostituído é o ser por excelência, é Deus, pois ele é o amigo supremo para cada indivíduo, pois ele é o reservatório comum, inesgotável do amor. Através da imagem da prostituição, essa antiga associação é profanada, isto é, recolocada em

\footnotetext{
${ }^{3}$ Para um estudo das diferentes formas de figuração do poeta caminhante, desde o pré-romantismo, é fundamental a leitura do ensaio de Jacques Rancière, "Transportes da liberdade" (Em RANCIÈRE, J. Políticas da escrita. São Paulo: Editora 34, 1995:105-139).
} 
função de um novo uso, em que os valores do uno, do próprio e da propriedade - no que afetam tanto a moral quanto a estética e a economia burguesas - são abalados. Tomamos a esse respeito a definição de Giorgio Aganbem:

E se consagrar [sacrare] era o termo que designava a retirada das coisas da esfera do direito humano, profanar significava, por oposição, restituí-las ao livre uso pelos homens. [...] O uso é, pois, sempre uma relação com o inapropriável, refere-se às coisas na medida em que estas não podem tornar-se objeto de posse.

Com Baudelaire, o gesto ambíguo da profanação faz com que a poesia recomece, impropriamente moderna, como poesia do fim, isto é, como gesto em que o novo é desentranhado do arruinamento mesmo da história passada, da imagem decadente dos sonhos de plenitude . Conforme diz ele da experiência do tempo, "Não podemos olvidar o tempo a não ser servindo-nos dele”. 'É essa experiência do tempo, como perda e retorno, repetição e transformação, que ele nos devolve, plantado no solo agora revolvido das certezas modernas, do mesmo modo como o faz com a experiência da linguagem. Tanto em uma quanto em outra, traz à cena antigos mitos, destituídos de seus ritos, junto com antigos ritos, destituídos de seus mitos - a alegoria é a representação plástica e temporal desse processo duplo, transitivo, que aproxima e tensiona, separa e reune presente e passado, eu e outro, começo e fim, retórica convencional e experiência de crise. ${ }^{4}$

Um século depois, Adília Lopes, ou Maria José da Silva Viana Fidalgo de Oliveira, se apropria desses mesmos procedimentos - ironia, ambigüidade, reversibilidade, transitividade, pluralização - para reencenar ainda mais uma vez a poesia como gesto de profanação. Do mesmo modo que em Baudelaire, com Adília a poesia parece que ganha impulso para recomeçar em uma direção ainda insuspeitada, novamente como uma continuação do fim, do fim do mundo (título de um de seus livros de poemas) e da literatura modernos, tantas vezes anunciado nesse nosso fim ou início de século, fazendo outra vez equivalerem-se o fim e o começo.

De Adília já disse o poeta português Nuno Júdice ter sido ela a responsável pela demolição do edifício da poesia do século XX. ${ }^{5}$

\footnotetext{
${ }^{4}$ Retomamos aqui a análise da relação entre jogo, mito e rito, feita por Émile Benveniste e mencionada por Giorgio Agamben, que dela não dá referência bibliográfica, em "Elogio da profanação" (Op. cit.: 107).

${ }^{5} \mathrm{O}$ poeta emitiu essa opinião sobre a poesia de Adília Lopes em depoimento sobre a poesia moderna e contemporânea portuguesa apresentado durante o co-
}

* (AGAMBEN, Giorgio. Profanações. Lisboa: Cotovia, 2005: 113 e 119.)

(BAudelaire, C. "O meu coração a nu". Op. cit.: 92.) 
(LOPES, Adília. Obra. Lisboa: Mariposa Azual, 2000: 156)

-(LOPES, A. Obra. Op. cit.: 21.)
De novo, uma poesia nascida das ruínas? De novo, uma poesia feita de ruínas? "Tudo se repete ad infinitum", " parece nos responder ela, em um de seus primeiros livros. Ao mesmo tempo fornece o mote para a definição da linguagem que irá marcar todos os seus livros seguintes, em que associa a repetitividade - de palavras, de personagens, de esquemas narrativos, de achados verbais - a um recomeço constante, reivindicando, assim, uma compreensão anacrônica de tempo em que tanto a idéia de origem quanto a de fim são desestabilizadas, associadas como o são a um agora e um sempre constantes: "A minha história/ é outra/ e começa agora/ Estou sempre/ a começar.

Onde começam e onde terminam as coisas? Onde começam e onde terminam o poema, a prosa, a realidade, a ficção, a literatura? Justamente por colocar em movimento essa máquina de fazer recomeçar e terminar, indefinidamente, a poesia de Adília se caracteriza por uma proliferação que, de novo, abala limites e desloca a idéia de singularidade do âmbito do único e do puro para o da pluralidade e do híbrido. Pluralidade das inumeráveis máscaras e personagens, em que se desdobra o eu enunciador de seus textos, manifestada ainda na serialidade ao mesmo tempo repetitiva e multiplicada de poemas. E que passa também pelo incontável número de referências, alusões e citações explícitas de artistas e obras os mais diversos, até a descontextualização e a re-contextualização de formas discursivas as mais disparatadas, da expressão à narração, da anedota à erudição, da bíblia ao romance policial, de Proust aos grafiteiros de Lisboa. E tudo isso de modo a fazer conviver também o ingênuo e o perverso, a tristeza e o humor irônico, a consciência do mal e a fé religiosa, o desencanto e uma expectativa inesperadamente utópica...

Através dessa experiência de repetição e recomeço de formas, tanto as já fixadas pela tradição culta quanto as associadas à memória popular e à cultura midiática, Adília esboça uma experiência da escrita que parece avessa a toda e qualquer separação sacralizante - efeito que atinge também a possibilidade de sua definição unívoca por um determinado valor de contemporaneidade. Será por isso pós-moderna? De novo moderna? De certa forma moderna? Impropriamente moderna? Literária? Pop? Ao mesmo tempo, e impropriamente, literária e pop? Essas categorias, na verdade to-

lóquio internacional A poesia portuguesa e o imaginário europeu, realizado na Universidade de Utrecht em junho de 2007. 
das as categorias, melhor dizendo, o processo mesmo de categorização é colocado em movimento, ou em uso, pela máquina poética de Adília Lopes, que a tudo re-une, re-convoca, exercitando a linguagem como prostituição, profanação, multiplicação, lembrando de novo Baudelaire: "O que é a arte? Prostituição. O prazer de estar nas multidôes é uma expressão misteriosa do gozo da multiplicação do número".

Desse modo, a experiência da escrita é encenada como exterioridade e impropriedade constantes - suspensão de limites. Esses limites, aliás, são justamente todos aqueles que Michel Foucault já associava aos procedimentos modernos de organização e institucionalização discursiva: a origem autoral, a divisão em disciplinas, o critério de verdade, os mecanismos de circulação e recepção." Através de sua suspensão, da reversibilidade entre o próprio e o impróprio, em seus diferentes sentidos, Adília Lopes faz recomeçar mais uma vez, pelo fim, a história da literatura, intensificando-a até o ponto necessário para mais uma vez liberá-la de sua apropriação institucionalizante e colocá-la à beira do ainda inominado. Não por acaso, seu primeiro livro intitula-se Um jogo bastante perigoso e abre com uma dupla epígrafe, em que aparece justo a imagem do abismo. A primeira, extraída do livro Bela Adormecida, da romancista portuguesa Agustina Bessa-Luís, remete a um mito tradicional, reativado pela romancista e, novamente, pelo uso que dela faz Adília, relacionando-o a uma segunda epígrafe, um fragmento de conto do livro Contos Exemplares, de Sophia de Melo Breyner Andresen:

Era a pura verdade e, embora a Bela adormecida tivesse um rosto lindo como uma flor, os cem anos lá estavam, além dos dezesseis que ela tinha quando adormeceu.

Compreendia que agora era ela que ia cair no abismo. Viu que, quando as raízes se rompessem, não se poderia agarrar a nada, nem mesmo a si própria. Pois era ela própria o que agora ia perder.

Em entrevista à revista Inimigo Rumor, Adília considera as epígrafes um gesto de repetição do fundamento literário, marcas de orientação, como "cartazes gigantes à entrada das cidades, quando se chega de auto-estrada”. "Mas também vê, nas aí referidas, o "mergulho até ao fundo do pantanal, da fossa, como se eu fosse Prometeu, que vai buscar o fogo às profundezas do lodo", "temporada no inferno" - abismo de que a literatura seria ao mesmo tempo a imagem e a possibilidade, perigosa, de salvação. Nessas epígrafes,
(BAUDELAIRE, Charles. "O meu coração a nu". Op. cit.: 25)

(FOUCAult, Michel. L'Ordre du discours. Paris: Gallimard, 1971)

•(LOPES, A. "Entrevista". Em: Inimigo rumor. Rio de Janeiro: Sette Letras, $\mathrm{n}^{\circ}$ 10, novembro de 2001: 19) 
(LOPES, A. Obra. Op. cit.: 335) portanto, reconhece uma dívida e um enraizamento e, ao mesmo tempo, delas desentranha a forma mesma de sua desestabilização e vertigem, como faz com o tecido das outras inumeráveis referências que compóem a singularidade de seu discurso.

Misturando a referência prosaica do trânsito das auto-estradas à viagem rimbaudiana ao inferno, ao mergulho de Prometeu no lodo, ao afundamento depressivo de sua própria identidade - todos por sua vez associados, irônica e ambiguamente, ao despertar de uma bela adormecida ao mesmo tempo jovem e mais que centenária -, Adília faz mais uma vez conviverem passado e presente, mito e ficção, literatura e senso-comum, através da imagem vertiginosa de suspensão dos limites entre excesso e abismo, tudo e nada, fim e recomeço. Suspender limites, solicitar fundamentos, não pela oposição ou pela exclusão, mas ao contrário, colocando em circulação, todas juntas, reversíveis, as coisas do mundo, e da literatura, pode ser de fato considerado como o motor da escrita sinestésica ${ }^{6}$ de Adília Lopes: "Mas eu/ não morro/ nunca/ e eternamente/ busco/ e consigo/ a perfeição/ das coisas / porque sou/ ateniense/ e sou grega”, diz ela no poema À maneira de Vieira, ${ }^{7^{*}}$ pois “... não se separa de graça/ o doce de framboesa do remédio misturados/ é assim nos livros/ é assim nas infâncias/ e os livros são como as infâncias", explica adiante o poema "Memórias das infâncias".

Remédio e doença, farmakon, portanto - como sugere a referência socrática contida nesses versos -, a prática da literatura é a de solicitação do fundamento e do abismo, do fundamento como abismo, do abismo como fundamento. Do mesmo modo, a solicitação da totalidade, da perfeição, em Adília não exclui, ao contrário supõe o inacabamento, como a repetição supõe o desdobramento, e a presença o vazio. "A arte é um modo de lidar com a ausência. E

${ }^{6}$ Como sinestésica Adília identifica a capacidade segundo ela própria a todo o poeta de reunir diferentes facetas e valores, como, no seu caso, o pop e conceitual . CF. a entrevista já citada, p.21.

${ }^{7}$ No ensaio "De demônios e espelhos: Adília Lopes e o imaginário europeu", faço uma leitura desse poema relacionando-o ao cristianismo postulado por Adília e à idéia de perfeição e totalidade defendida pelo padre Antônio Vieira em um de seus sermões (PEDROSA, C. "De demônios e espelhos: Adília Lopes e o imaginário europeu” In: P: Portuguese Cultural Studies. Utrecht: Universidade de Utrecht, novembro de 2007). Também comento aí a relação entre o poema e os famosos versos de Cesário Verde, em "O sentimento de um ocidental", sobre a busca da perfeição das coisas. Explicitamente considerado por Adília uma importante referência para sua prática poética, considerado o introdutor em Portugal da modernidade baudelaireana, Cesário sugere mais uma forma de entrada na discussão das relações de Adília com a modernidade baudelairiana. 
por isso é tão perigosa. Nunca é a alegria da presença”. Essa relação paradoxal entre presença e ausência, salvação e perigo, subjaz à forma como na escritura de Adília se relacionam as idéias de fim e de começo, tradição e inauguração, memória e experiência - experiência abismada da subjetividade, da literatura, do tempo.

Por isso proliferam em sua escritura memórias e infâncias, cuja presença excessiva serve paradoxalmente para fragilizar o valor de fundamento a elas convencionalmente atribuído - efeito repetido como que em abismo na própria grafia pluralizada excessivamente no título do poema há pouco referido. É significativo, aliás, que a infância em Adília possa servir à definição mesma de sua linguagem, pelo excesso repetitivo, como faz Oswaldo Silvestre ao apontar com precisão "as lenga-lengas da menina Adília” . E que retorne sempre repetidamente, como lengalenga, através das imagens do duplo que parecem organizar sua memória, sempre referida a cenas de um antigo, pequeno e perverso cotidiano de família e vizinhança: mãe e filha, mãe e avó, tia e avó, amigas íntimas, irmãs siamesas, todas meninas exemplares mas nem tanto...8 à procura de príncipes também eles encantados mas nem tanto. Afinal, "Guilherme chamava-se Hipólito", * diz o epílogo da história de Maria Cristina Martins, que se abre com uma referência ao quadro de um duplo, o "Les deux soeurs" de Théodore Chassériau, e se desdobra em meio a obviedades e incertezas que afetam o próprio nome: "Chamo-te Maria Cristina/ Como te chamas, Maria Cristina?”*

Nesse processo, a identidade pessoal se multiplica em muitas figurações e ficcionalizações, em que as imagens do duplo, novamente atualizando a relação entre repetição e desdobramento, excesso e ausência, familiaridade e estranheza, ao mesmo tempo afirmam e rasuram, como se vê, até mesmo a propriedade do nome. Desde o jogo de associação e substituição entre Marias, Martas, Arimas e Mariannas, passando pela interação entre nome e pseudônimo autoral que faz confundirem-se Maria José e Adília: "Adília Lopes e Maria José da Silva Viana Fidalgo de Oliveira são uma e a mesma pessoa. São eu. Como uma papoila é poppy. E muitos outros nomes que eu não sei. A Adília Lopes é água no estado gasoso, a Maria José é a mesma água no estado sólido.”* Até a pró-

\footnotetext{
${ }^{8}$ Flora Süssekind já apontou para a importância dos procedimentos de repetição e duplicação na poesia de Adília Lopes, no texto "Com outra letra que não a minha”, que serve de posfácio à antologia de poemas de Adília (SÜSSEKIND, Flora. "Com outra letra que não a minha”. Posfácio a LOPES, Adília. Antologia. São Paulo: Cosac \& Naify, 2002.).
}

•(LOPES, A. Le vitrail/la nuit* $A$ árvore cortada. Lisboa: \&etc., 2006: 82.)

"(SILVESTRE, Osvaldo. "As lenga-lengas da menina Adília". In: LOPES, Adília. Florbela Espanca espanca. Lisboa: Black Sun, 1999: 38)

(LOPES, A. Obra. Op. cit.: 199.)

* (LOPES, A. Obra. Op. cit.: 194.)

"(LOPES, A. "Entrevista". Op. cit.: 18-19.) 
(LOPES, A. Obra. Op. cit.: 339)

-(MILLER, Jacques-Alain "Extimité". Em BRACHER, Mark et al. (ed.). Lacanian Theory of Discourse. Subject, Structure and Society. New York: New York University Press, 1994.)

(LOPES, A. Le vitrail//a nuit* A árvore cortada. Op. cit.: 50.)

(BAUDELAIRE, C. "O meu coração a nu". Op. cit.: 68.$)$ pria duplicidade que a poeta enxerga entre as duas partes de "Maria José", como mostra irônico o poema "Z/S", em alusão, invertida, claro, à novela balzaquiana tornada célebre pela leitura que dela faz Roland Barthes.

Através dessas imagens, toda forma de identidade - feminina, poética, familiar, social - é posta de modo relacional, extimo, segundo a formulação lacaniana, ou transitivo, se recuperamos de novo a compreensão de lirismo que Laurent Jenny extrai da poesia baudelairiana. Transitivas, extimas, tensas, instáveis, elas mobilizam e reúnem então profanamente valores e afetos diversos, como, a propósito das relações entre mãe e filha, vai afirmar a poeta: "Mãe e filha são como duas árvores que estão perto: vivem e morrem das sombras que fazem uma à outra reciprocamente". Desse modo, sombreadas, essas relaçôes originárias, aparentemente retomadas e repetidas com ingenuidade - como de resto aí toda lembrança, afetiva ou literária - perdem seu fundamento, retornando re-originadas, e lembrando assim, segundo um paradigma paradoxalmente infantil, irônico e perverso, o espelho ao mesmo tempo doméstico e misterioso de Alice, menina "exemplar" de Lewis Carrol que Adília revisita junto com as meninas também "exemplares" da Condessa de Ségur, uma e outras a ajudando a rever sua infância, fazendo-a mergulhar num baú/ alçapão de imagens e histórias sem fundo, sem fim, sem começo nem fim. ${ }^{9}$

Não por acaso, articulando proliferação e afundamento - dupla face da vertigem -, a infância em Adília funciona associada à queda, e dessa forma sua re-originação se associa também à re-originação de cenas da infância mítica da humanidade, com a queda do Paraíso. Entrelaçam-se aqui dois movimentos da queda. Se o movimento da memória é como a queda num alçapão sem fundo que, através da proliferação de cenas, figura, paradoxalmente, a falta de fundamento, de estabilidade e perenidade das imagens da origem e do devir histórico, por outro lado, também a própria origem é encenada como queda a partir da qual essa memória e esse devir encontram seu instável fundamento transformado em motor da criação. Lembremos a propósito Baudelaire: "A teologia. O que é a queda? Se é a unidade tornada dualidade, foi Deus quem caiu. Noutros termos, a criação não seria a queda de Deus?"*

\footnotetext{
${ }^{9}$ As referências a Madame de Ségur estão espalhadas pelos textos de Adília, mas pode-se ressaltar, no livro $\mathrm{O}$ decote da dama de espadas, as duas seçôes intituladas "Os desastres de Sofia" e "As meninas exemplares", além do poema "Os desastres da boneca de Sofia”.
} 
Em Adília, a recuperação da imagem religiosa, ética e estética da queda, aparece desde logo associada à relação ao mesmo tempo luminosa e sombria, como vimos, entre mãe-filha:

Gostava de cair. Há nisso, talvez, masoquismo, perversidade. Mas também há sentido de responsabilidade porque as bonecas eram minhas filhas e uma mãe não deixa cair as filhas no chão. Digamos, a brincar, que a minha mãe me deixava cair ao chão. Penso que isto que acabo de escrever é estranho.

Em outro momento, inscritos numa mesma página, em posição ao mesmo tempo complementar e invertida, como diante de um espelho perverso, dois poemas sobre a queda - A queda optimista e A queda pessimista - convidam novamente à re-união paradoxal de bem e mal, claro e escuro, perda e originação. Diz o primeiro: Cair do cavalo/ cair da escada/ cair em mim/ o rés-do-chão é tão bonito/ o chão é tão bom/... é a libertação da queda/ de Adão e Eva/ é Adão que me estende a mão". No segundo, a forte síntese parece acentuar o valor antagônico: "Escuro como breu/ o chão me comeu". Queda e elevação se confundem desse modo: "Vontade/ de dar pulos até Deus/ Vontade de me afundar/ até ao Diabo", diz outro poema.

Ao inscrever sua origem como queda e simultânea elevação, re-união profanadora de bem e mal, deus e diabo, Adília Lopes mais uma vez suspende limites e propóe uma busca da totalidade feita transgressivamente do inacabado, do impuro, sua prática de escrita proliferante e abismada encontrando aí uma diretriz também ética, através da qual retorna de novo profanada a relação entre a poesia e a religião cristã. "Cristo foi o homem mais inteligente que veio ao mundo. E eu concordo porque a caridade é a verdadeira inteligência. Não importa saber se Cristo é deus feito homem ou que espécie de relações estabelece com o Espírito Santo"., pois "Sem caridade/ a literatura não vale". *

Não se pode deixar de identificar aí de novo a relação entre Adília e Baudelaire, que no fragmento XIX de Meu coração a nu, após reivindicar como própria de todo homem a simultânea solicitação de Deus e do Diabo, associa essa característica à caridade, segundo ele outro nome da libertinagem. Para a nossa poeta, essa virtude cristã se associa a uma paz também satânica - "Paz rima/ com Satanás" -* que ela opõe à beleza como objetivo da salvação a ser proporcionada pela literatura. "A arte é feita para construir a paz. Não é um esgrimir no vazio”, responde ela à pergunta formu-
(LOPES, A. Le vitrail/la nuit* $A$ árvore cortada. Op. cit.: 50)

' (LOPES, A. Obra. Op. cit.: 371.)

* (LOPES, A. Le vitrail/la nuit* A árvore cortada. Op. cit.: 41 .)

"(LOPES, A. Obra. Op. cit.: 430)

$*(: 391$.

(BAudelaire, C. "O meu coração a nu". Op. cit.: 61.)

' (LOPES, A. Obra. Op. cit.: 349) 
- (LOPES, A. Le vitrail/la nuit* $A$ árvore cortada. Op. cit.: 82.$)$

lada já no título - "Haverá uma beleza que nos salve?" - do último texto de seu pelo menos provisoriamente último livro. "Segundo essa proposta de salvação, em que a paz se depreende da caridade que solicita a totalidade imperfeita e inacabada das coisas do mundo - imperfeição e inacabamento que ressoam aí no desdobramento diabólico da própria divindade, na figuração em queda da criação, na transformação do excesso em abismo -, Adília Lopes está solicitando o satanismo ético de Baudelaire, mas para recolocá-lo em uso, profanado, de modo a repensar o lugar do poeta nessa nossa contemporaneidade de novo assombrada pelos espectros do fim e do recomeço.

Para isso, intensifica esses procedimentos que desde Baudelaire se tornaram fundamentais à poesia moderna - a ironia, a transitividade, a fragmentação -, desalojando-os de seu lugar já apropriadamente literário de culto, transformando-os em objeto de um jogo irreverente e produtivo. Repetição e proliferação funcionam desse modo como máscaras impróprias, perversas, que convocam essa tradição e ao mesmo tempo a põem em movimento de queda. ${ }^{10}$ Nessa queda, Baudelaire reaparece através da negação de duas das imagens mais significativas de sua poesia, assim como de toda a poesia moderna - a da luta, ou esgrima, e a da viagem - justamente aquelas consideradas também fundamentais à tradição clássica da alegoria, em seu valor de busca do sentido. ${ }^{11} \mathrm{O}$ poeta, no entanto, vai fazer da alegoria um instrumento de problematização da própria possibilidade de busca e de sentido. Afinal sua esgrima é errante, noturna, fantasmática, seus navios não saem do cais... Baudelaire vive atormentadamente a modernidade como esse limiar entre fim e iminência, à revelia de todo projeto no qual, paradoxalmente, faz brotar a poesia moderna.

Cem anos depois, vivendo agora num tempo dito pós-moderno, mas também perceptível como limiar entre o que não cessa de terminar e o que ainda resta por vir, Adília Lopes nega explicitamente a compreensão de poesia tanto como fuga, convite à viagem, quanto como esgrima atormentada, antagônicas ambas à paz que tanto almeja: "A biblioteca baralhada/ quero arrumar/ aqui quase tudo é desordem/ e eu quero ficar/ Isto não é o convite à viagem/ é

\footnotetext{
${ }^{10}$ Podemos considerar também que através desse procedimento Adília submete a um modo satânico, irônico, de espelhismo as formas da acumulação e da propriedade características da economia e da cultura capitalista.

${ }^{11}$ Importantes referências sobre a tradição da alegoria são fornecidas em LABARTHE, Patrick (Baudelaire et la tradition de l'allégorie. Génève: Droz, 1999).
} 
o convite a ficar...". Desse modo, se insurge contra a tradição com a qual dialoga com tanta intensidade, como vimos. Mas na verdade, para mais uma vez, fiel à herança baudelairiana, retirar a aura do poeta. Dessa vez, a do poeta atormentado que se tornou ao longo do século XX arauto de um indizível, premiado e embalado para presente clichê apriorístico que vai se transformando em motivo de realocação sublimizante e garantia de canonização. ${ }^{12}$

Apostando na possibilidade de retorno e recomeço produtivo do processo de desestabilização proposto por Baudelaire, em detrimento desse efeito no qual ele foi circunscrito e legitimado, Adília associa agora o poeta a uma prosaica e pervertida mulher-a-dias que combina ordem e desordem, na arrumação da casa e da biblioteca, frágeis mas acolhedores castelos de cartas armados, apesar de tudo, entre a memória e a iminência da catástrofe. Tentando evitar a melancolia autocomplacente de grande parte das apropriaçóes pós-modernas da poesia baudelairiana, Adília vivencia, sim, a poesia de novo como exercício de perda de seu próprio fundamento, de todo fundamento. Mas tenta fazer dessa perda a possibilidade mesma de solicitação de tudo, aqui mesmo, agora mesmo: "Acabou/ o tempo/ das rupturas/ Quero/ ser/ reparadora/ de brechas". Ironia, profanação, proliferação, transitividade são as engrenagens desse exercício antropofágico, de caridade e comunhão, sinônimo aí, talvez, de uma difícil e cruel alegria ${ }^{13}$ com a qual a poeta tenta atualizar um novo sentido de experiência em nossos tempos de fim da experiência. ${ }^{14}$ Adília e Baudelaire: leituras do fim.

\footnotetext{
${ }^{12}$ No ensaio já mencionado, Osvaldo Silvestre ressalta que Adília, embora se exercite na consciência do abismo ente linguagem e realidade fenomenal, recusa a inserção na instituição da indizibilidade sublime que legitimaria muito da poesia contemporânea.

${ }^{13}$ Referimo-nos aí à noção nietzscheana de alegria, tal como desenvolvida por Clément Rosset (ROSSET, C. Alegria: a força maior. Rio de Janeiro: Relume Dumará, 2000.).

${ }^{14}$ Talvez seja interessante nesse sentido associar o valor da infância na poesia de Adília àquele proposto por Giorgio Agamben, justo a propósito da idéia benjaminiana de fim da experiência (AGAMBEN, G. Infância e história. Destruição da experiência e origem da história. Belo Horizonte: UFMG, 2005).
} 


\section{Celia Pedrosa}

Celia Pedrosa é professora de Literatura Brasileira e Teoria da Literatura na Universidade Federal Fluminense. Com apoio do CNPq, coordena grupo de pesquisa sobre Poesia, Contemporaneidade, Visualidade. Coordena também projeto de pesquisa sobre Poéticas contemporâneas: subjetividades e identidades em devir, em convênio CAPES com a Universidade do Porto. Sobre o tema, além de inúmeros ensaios, tem publicados, como organizadora, entre outros, os livros Poesia e contemporaneidade; leituras do presente (Argos, 2001), Poéticas do olhar e outras leituras de poesia (7 Letras, 2006), ambos com Maria Lucia Barros Camargo, e Crítica e Valor (7 Letras, 2007), com Flora Sussekind e Tânia Dias.

\section{Resumo}

Palavras-chave: Modernidade; Contemporaneidade; Profanação; Subjetividade; Historicidade
Key words: Modernity; Contemporaneity; Profanation; Subjectivity; Historicity

Mots-clés: Modernité; Contemporanéité; Profanation; Subjectivité; Historicité
Recebido em $16 / 03 / 2007$

Esse ensaio se propóe a avaliar o uso profanador feito pela poeta portuguesa Adília Lopes da herança baudelairiana, focalizando os procedimentos de ironia, figuração, fragmentação e transitividade com que em ambos se encena a subjetividade lírica e associandoos a um modo impróprio de relação com a modernidade e a contemporaneidade, compreendidas como experiências paradoxais de fim e recomeço.

\section{Abstract}

This essay evaluates the desecrating use of the Baudelairean heritage by the Portuguese poet Adília Lopes. It focuses on the procedures of irony, figuration, fragmentation, and transitivity with which lyrical subjectivity is represented by both poets, and associates them with an improper way of relating to modernity and the contemporary, which are viewed as paradoxical experiences of the end and a new beginning.

\section{Résumé}

Cet essai se propose d'évaluer l'usage profanateur fait par la poète portugaise Adília Lopes de l'héritage baudelairien, en mettant l'accent sur les procédés de l'ironie, de la figuration, de la fragmentation et de la transitivité dont les deux écrivains se servent pour mettre em scène la subjectivité lyrique et em les associant à um mode impropre de rapport à la modernité et à la contemporanéité, comprises em tant qu'expériences paradoxales de fin et de recommencement. 